\title{
Suppression of Tropical Cyclone Development in Response to a Remote Increase in the Latent Heat Flux over the Kuroshio: A Case Study for Typhoon Chaba in 2010
}

\author{
Keita Fujiwara, Ryuichi Kawamura, and Tetsuya Kawano \\ Department of Earth and Planetary Sciences, Faculty of Science, Kyushu University, Fukuoka, Japan
}

\begin{abstract}
This study investigated the remote impact of an increase in latent heat flux (LHF) over the Kuroshio on tropical cyclone (TC) development, using a cloud-resolving model. A control run and a sensitivity experiment with Kuroshio's LHF artificially enhanced were performed for Typhoon Chaba in 2010. The TC development simulated in the sensitivity experiment was suppressed as compared with the control run. The sensitivity experiment demonstrated that eyewall convection and the associated TC secondary circulation were suppressed by a decrease in equivalent potential temperature $\left(\theta_{e}\right)$ around the eyewall through the lower $\theta_{e}$ penetration into the inner core region in the boundary layer. The dynamic features of the TC were also altered by the attenuated TC secondary circulation through the inhibition of the inward advection of the absolute angular momentum. The super-gradient tangential velocities in the inner core were smaller than those in the control run. Such thermodynamic and dynamic changes were remotely induced by the decrease in moisture import from the Kuroshio. Since the increased LHF facilitated the development of a surface low over the Kuroshio, the intensified low further accumulated the Kuroshio's vapor and suppressed low-level northeasterlies toward the TC, resulting in interrupting the moisture import into the TC.

(Citation: Fujiwara, K., R. Kawamura, and T. Kawano, 2020: Suppression of tropical cyclone development in response to a remote increase in the latent heat flux over the Kuroshio: A case study for Typhoon Chaba in 2010. SOLA, 16, 151-156, doi:10.2151/ sola.2020-026.
\end{abstract}

\section{Introduction}

Changes in tropical cyclone (TC) intensity are closely linked to latent heating $(\mathrm{LH})$ due to vapor condensation within a TC system. A large amount of moisture in the vicinity of the TC center is composed of vapor influx from the outer region as well as local evaporation in the inner region (e.g., Braun 2006; Yang et al. 2011; Kudo et al. 2014; Makarieva et al. 2017; Takakura et al. 2018). Moisture import across a few thousand kilometers influences TC development over the Western North Pacific in boreal summer (Hegde et al. 2016; Fujiwara et al. 2017). These studies suggest the importance of moisture influx from the remote ocean to TC intensification.

Recently, Fujiwara et al. (2020) (hereafter, F2020) reported that the Kuroshio remotely influences TC development in boreal fall, although it was a case study for Typhoon Chaba in 2010. Concurrent with the northward-moving Chaba over the Philippine Sea, an eastward-migrating anticyclone was located around Japan during Chaba's development stage (Fig. 1a). Such a synoptic environment enhanced the meridional pressure gradient along the Pacific coast of Japan and induced low-level northeasterly flows over the Kuroshio (Fig. 1b). Areas of strong surface evaporation accompanied by the northeasterly winds expanded from the Kuroshio to the vicinity of Chaba (Fig. 1b), suggesting that the

Corresponding author: Keita Fujiwara, Department of Earth and Planetary Sciences, Faculty of Science, Kyushu University, 744 Motooka, Nishi-ku, Fukuoka 819-0395, Japan. E-mail: keita.fujiwara926@gmail.com.
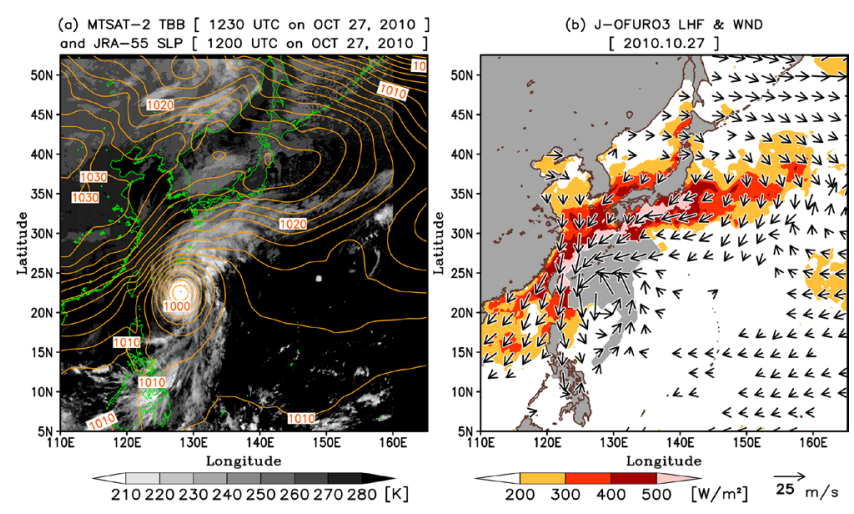

Fig. 1. (a) Horizontal maps of the brightness temperature (shading) observed by the Multi-functional Transport Satellite 2 (MTSAT-2) at 1230 UTC on 27 October 2010, and the SLP (contours) derived from the Japanese 55-year Reanalysis data (Kobayashi et al. 2015) at 1200 UTC on 27 October 2010. The contour interval is $4 \mathrm{hPa}$. (b) Horizontal maps of daily mean surface turbulent latent heat flux (shading) and horizontal winds at a height of $10 \mathrm{~m}$ (vectors) derived from the Satellite-derived air-sea flux dataset (J-OFURO3; Tomita et al. 2019) on 27 October 2010. The reference arrow is $25 \mathrm{~m} \mathrm{~s}^{-1}$. Wind speeds of less than $5 \mathrm{~m} \mathrm{~s}^{-1}$ are not drawn. The gray shading shows the area of missing data in the J-OFURO3.

vapor evaporated from the Kuroshio was transported into the inner region of the TC. Under these environmental conditions, artificially reduced or removed latent heat flux (LHF) over the Kuroshio suppressed Chaba's development before it overlapped with the Kuroshio. The penetration of midlatitude dry air, which could gain little or no vapor supply from the Kuroshio, decreased the values of equivalent potential temperature $\left(\theta_{e}\right)$ in the planetary boundary layer (PBL) within the inner core, which suppressed the eyewall convection, resulting in the deceleration of TC development.

However, there is still room for increasing the reliability of remote influences of the Kuroshio on TC development. F2020 focused specifically on the thermodynamic impacts of the Kuroshio on eyewall convection and $\theta_{e}$ in the inner core. On the other hand, dynamic processes (e.g., a vortex spin-up process) were also crucial for TC intensification (e.g., Krishnamurti et al. 2005; Smith et al. 2014; Smith and Montgomery 2015). The inward advection of the absolute angular momentum (AAM) due to strong boundary-layer inflow is one of the major processes for the spin-up of TCs (e.g., Kepert 2001; Zhang et al. 2001; Smith et al. 2009). Thus, we also should have validated the results of F2020 in terms of the AAM transport in the inner core of the TC. Furthermore, although F2020 presented that TC development was inhibited in sensitivity experiments in which Kuroshio's LHF was reduced or removed, the question still remains whether the TC development accelerates conversely when the LHF is increased over that current. Thus, the objective of this study is to examine how the LHF increase over the Kuroshio remotely influences TC development and associated dynamic and thermodynamic processes. To address the objective, we specifically investigated Typhoon Chaba in 2010, which is the same TC analyzed in F2020. 

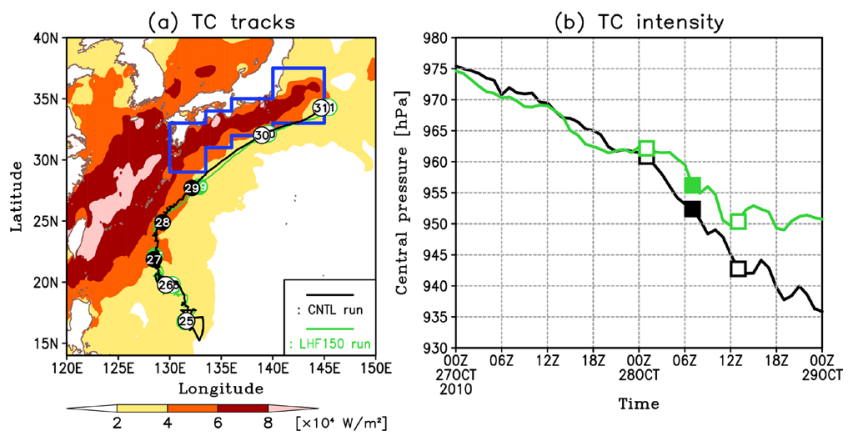

Fig. 2. (a) Tracks of Typhoon Chaba simulated by the CNTL run (black line) and the LHF150 run (green line). Opened and closed circles denote the locations of Typhoon Chaba at 0000 UTC each day. Horizontal map of the latent heat flux integrated from 1200 UTC on 24 October 2010, to 0000 UTC 31 October 2010 , in the CNTL run is also depicted. The domain where the LHF is modified in the LHF150 run is enclosed by blue lines. (b) Time series of the central pressure in the CNTL run (black line) and the LHF150 run (green line) at Chaba's development stage shown by closed circles in Fig. 2a. Closed squares denote the time of the maximum deepening rate. Open squares denote 6 hours before and after the time of the maximum deepening rate.

\section{Methods}

Numerical simulations of Typhoon Chaba were performed by the $0.04^{\circ}$-horizontal-resolution Cloud-Resolving Storm Simulator (CReSS version 3.4.1; Tsuboki and Sakakibara 2002). The horizontal resolution was enough to reproduce the rapid intensity changes of TCs and their inner core structures (Gentry and Lackmann 2010). The model physics was the same as that in F2020 (see Section 2.1 in F2020). The simulated domain in the CReSS covered $110^{\circ} \mathrm{E}-165.2^{\circ} \mathrm{E}$ and $5^{\circ} \mathrm{N}-52.52^{\circ} \mathrm{N}$. The simulation's start time was 1200 UTC on 24 October 2010, and the end time was 0000 UTC on 31 October 2010 . We used the $0.5^{\circ}$-resolution Japan Meteorological Agency (JMA) Global Spectral Model data (JMA 2013) for the initial and boundary conditions. The sea surface temperature (SST) fields were derived from the $0.25^{\circ}$-resolution Optimum Interpolation Sea Surface Temperature v2 based on the Advanced Very High Resolution Radiometer (OISST v2; Reynolds et al. 2007). This study included two simulations: a control simulation with a real SST distribution (hereafter, CNTL run) and a sensitivity experiment. In the CNTL run, surface evaporation along the Kuroshio predominated during the integration period (Fig. 2a). In the sensitivity experiment, we artificially increased by $50 \%$ the exchange coefficient of water over the Kuroshio region only (enclosed by blue lines in Fig. 2a) as compared with the CNTL run (hereafter, LHF150 run). The values of the LHF over the Kuroshio were approximately 50\% larger in the LHF 150 run than in the CNTL run during the simulation.

This study simply defined the TC deepening rate, $\varepsilon$, as

$$
\varepsilon(t)=\frac{C P(t-6)-C P(t+6)}{12},
$$

where $C P$ and $t$ are the central pressure of the TC and the time in hours, respectively.

\section{Results}

We first compare the TC's track and the temporal evolution of the CP between the CNTL and LHF150 runs in Fig. 2. The track of the TC in the LHF150 run was similar to that in the CNTL run (Fig. 2a). As for the CP, $\varepsilon$ reached its maximum at 0700 UTC on 28 October in both simulations. Very interestingly, the TC development around 28 October was slower in the LHF150 run than in the CNTL run (Fig. 2b), although we expected that the increase in the Kuroshio's LHF facilitated TC intensification. The value of the CP in the CNTL (LHF150) run was 961 (962) $\mathrm{hPa}$ at 0100 UTC and 942 (950) hPa at 1300 UTC. The suppression of TC intensification was contrary to our expectation, which might conflict with the results of F2020. To understand the difference in TC development between the two runs, we investigated the thermodynamic and dynamic features of the TC 6 hours before and after the time of the maximum $\varepsilon$, corresponding to the stage of the rapid TC development.

We next show the time evolution of the LH rate, $\theta_{e}$ within the inner core, and the TC secondary circulation in Fig. 3. During TC development in the CNTL run, LH around the eyewall increased significantly, and the secondary circulation became robust (Figs. $3 \mathrm{a}$ and $3 \mathrm{c}$ ). In accordance with a weak tendency of TC intensity in the LHF 150 run, the eyewall LH and the secondary circulation (Figs. 3e and $3 \mathrm{~g}$ ) were not very enhanced as compared with the CNTL run. It was suggested that, in the LHF150 run, the suppression of the eyewall convection was intimately linked to the weakening of the TC secondary circulation. A comparison of the values of the PBL- $\theta_{e}$ (e.g., contours with a value of $350 \mathrm{~K}$ and $360 \mathrm{~K}$ ) between the two runs revealed the penetration of the lower $\theta_{e}$ air toward the eyewall in the LHF150 run (Figs. $3 \mathrm{~d}$ and $3 \mathrm{~h}$ ). The reduction in the PBL- $\theta_{e}$ around the eyewall causes the inhibition of TC development (e.g., Riemer et al. 2010). In addition, convective instability in the near-surface layer within the inner core tended to weaken in the LHF150 run. These thermodynamic situations were very similar to those of F2020, which simulated the attenuated TC intensity in sensitivity experiments that modified the LHF over the Kuroshio. We suggest that the decrease in the PBL- $\theta_{e}$ around the eyewall may be responsible for the suppression of the eyewall convection in the LHF150 run.

To confirm the difference in TC development between the two runs in terms of dynamic processes, we show the radius-height cross sections of the azimuthally averaged tangential wind speed $\left(V_{t}\right)$ in Fig. 4 at the same time as in Fig. 3. In the CNTL run, the primary circulation around the radius of maximum $V_{t}$ (RMW) increased rapidly in 12 hours (Figs. 4a and 4c). It seems that the increases in the $V_{t}$ were associated with a sizeable amount of inward AAM advection due to strong PBL inflow (Fig. 4d). In contrast, the $V_{t}$ increases (Figs. $4 \mathrm{e}$ and $4 \mathrm{~g}$ ) and radial AAM advection (Fig. 4h) around the RMW were less evident in the LHF150 run. In both simulations, furthermore, the $V_{t}$ around the RMW exceeded the gradient wind speeds at 1300 UTC (Figs. 4c and 4g), indicating the behavior of super-gradient wind. Previous studies pointed out that the development of super-gradient wind resulted from the inward AAM advection due to TC secondary circulation (e.g., Smith et al. 2009; Qin et al. 2018). Thus, we suggest that reductions in the radial AAM advection in association with the attenuated secondary circulation can inhibit the TC spin-up process in the LHF150 run.

To investigate the time evolutions of the TC development in more detail, we show the height-time cross sections of dynamic and thermodynamic variables averaged within the TC inner core region. The size of the inner core was simply defined as a radius of $150 \mathrm{~km}$ from TC center, considering the results of Fig. 4. Very interestingly, significant differences between the two runs were apparent prior to the onset of the rapid TC development. From approximately $1800 \mathrm{UTC}$ on 27 October to 0100 UTC on 28 October, the $\theta_{e}$ below a height of $500 \mathrm{~m}$ within the TC inner core gradually increased in the CNTL run. LH and the associated PBL inflow (Figs. 5a and 5d) also showed an increasing tendency. The intensified inflow (in excess of $6 \mathrm{~m} \mathrm{~s}^{-1}$ ) created strong inward AAM advection (in excess of $8 \times 10^{5} \mathrm{~m}^{2} \mathrm{~s}^{-1} \mathrm{~h}^{-1}$ ), resulting in the enhancement of the $V_{t}$ (Fig. 5c). In contrast, the PBL- $\theta_{e}$ showed a decreasing tendency during that period in the LHF150 run (Fig. 5f). The lower $\theta_{e}$ inhibited the increase in LH and the associated inflow (Figs. 5e and 5h). The resultant weaker inward AAM advection contributed to slower increase of the $V_{t}$ (Fig. $5 \mathrm{~g}$ ). These results indicate that the change in thermodynamic processes before 0100 UTC on 28 October was a precursory signal for the onset of the rapid development.

A question that naturally arises from the above results is why 
(i) CNTL run

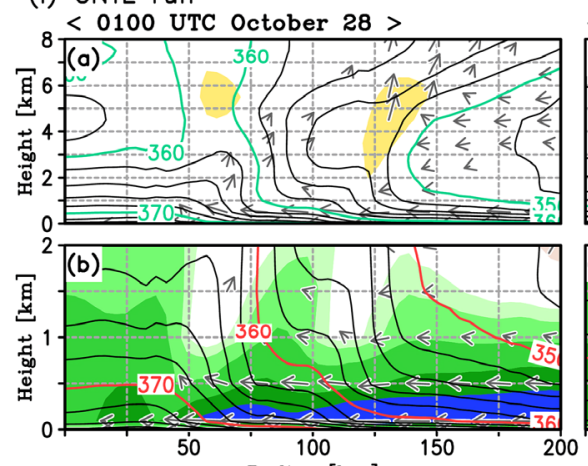

(ii) LHF150 run Radius [km]
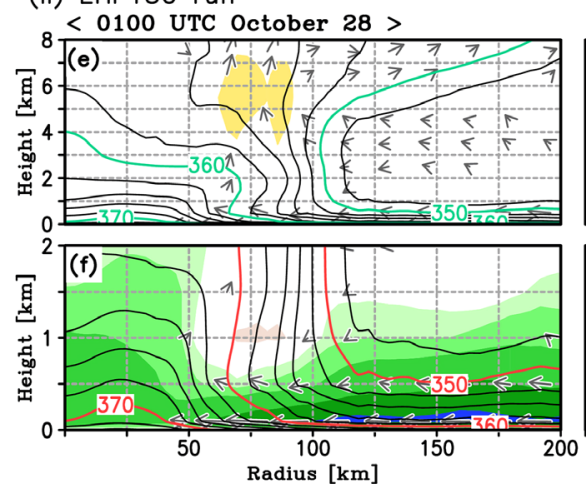
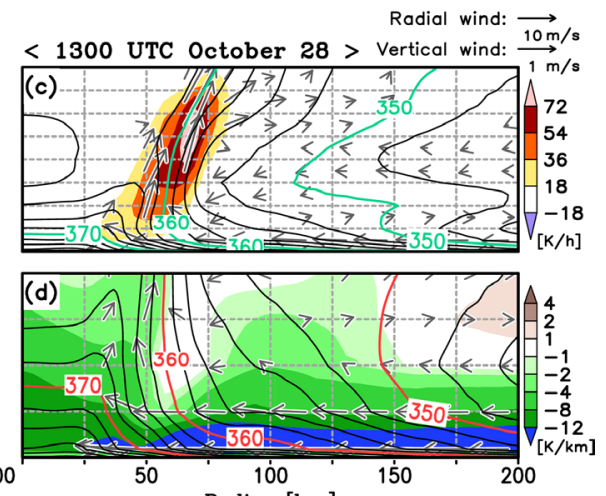

Radius [km] Radial wind: $\longrightarrow$ $<1300$ UTC October $28>$ Vertical wind: $\underset{10 \mathrm{~m}}{\longrightarrow} \mathrm{s}$
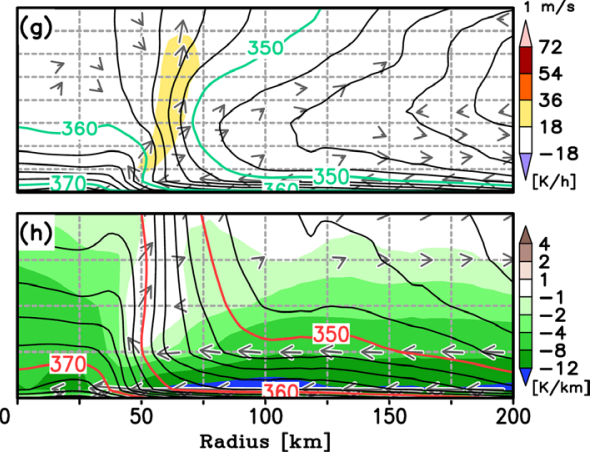

Fig. 3. (a and c) Radius-height cross sections of the azimuthally averaged latent heating rate (shading), $\theta_{e}$ (contours; $2 \mathrm{~K}$ intervals), and TC secondary circulation (gray vectors) in the CNTL run at 0100 UTC and 1300 UTC on 28 October 2010. (b and d) Radius-height cross sections of the azimuthally averaged vertical gradient of $\theta_{e}$ (shading), $\theta_{e}$ (contours; $2 \mathrm{~K}$ intervals), and TC secondary circulation (gray vectors) within the PBL in the CNTL run at $0100 \mathrm{UTC}$ and 1300 UTC on 28 October 2010. (e and g) Same as in Figs. 3a and 3c, but for the LHF150 run. (f and h) Same as in Figs. 3b and 3d, but for the LHF150 run.

(i) CNTL run
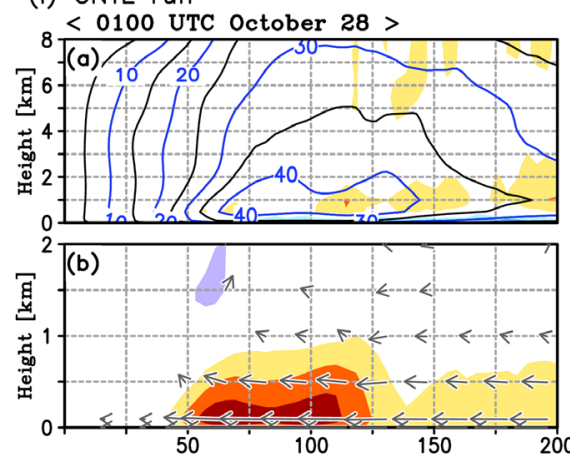

(ii) LHF150 run Radius [km]
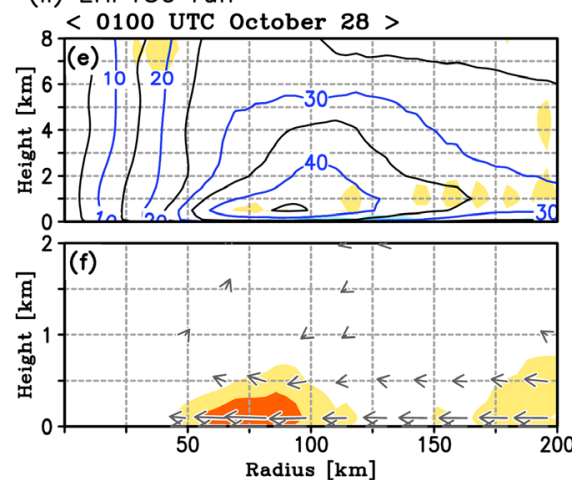
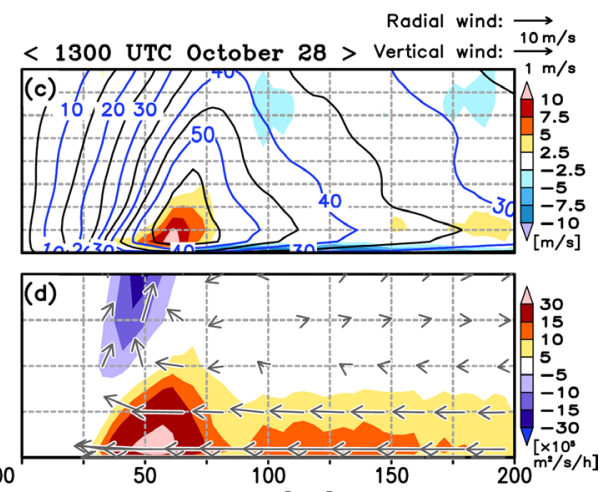

Radius [km] Radial wind: $\longrightarrow$
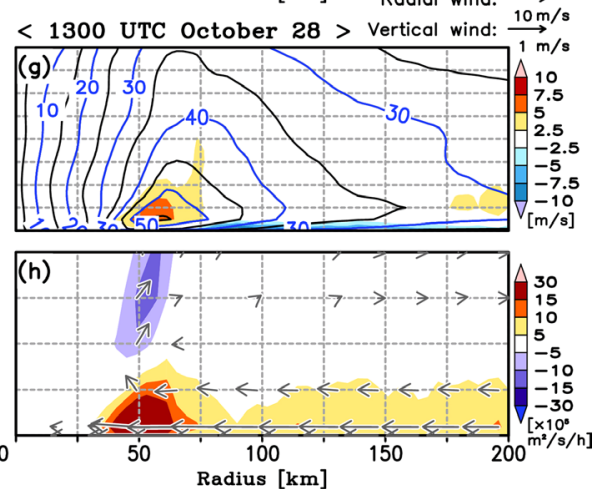

Fig. 4. (a and c) Radius-height cross sections of the azimuthally averaged tangential wind speed (contours; $5 \mathrm{~m} \mathrm{~s}^{-1}$ intervals) in the CNTL run at 0100 UTC and 1300 UTC on 28 October 2010. Differences in the tangential wind speed and gradient wind speed (the former minus the latter) are also drawn (shading). ( $b$ and d) Radius-height cross sections of the radial AAM advection (shading) and TC secondary circulation (gray vectors) within the PBL in the CNTL run at 0100 UTC and 1300 UTC on 28 October 2010. The unit of the radial AAM advection is $10^{5} \mathrm{~m}^{2} \mathrm{~s}^{-1} \mathrm{~h}^{-1}$. (e and g) Same as in Figs. 4a and $4 \mathrm{c}$, but for the LHF150 run. (f and $h$ ) Same as in Figs. 4b and 4d, but for the LHF150 run. 


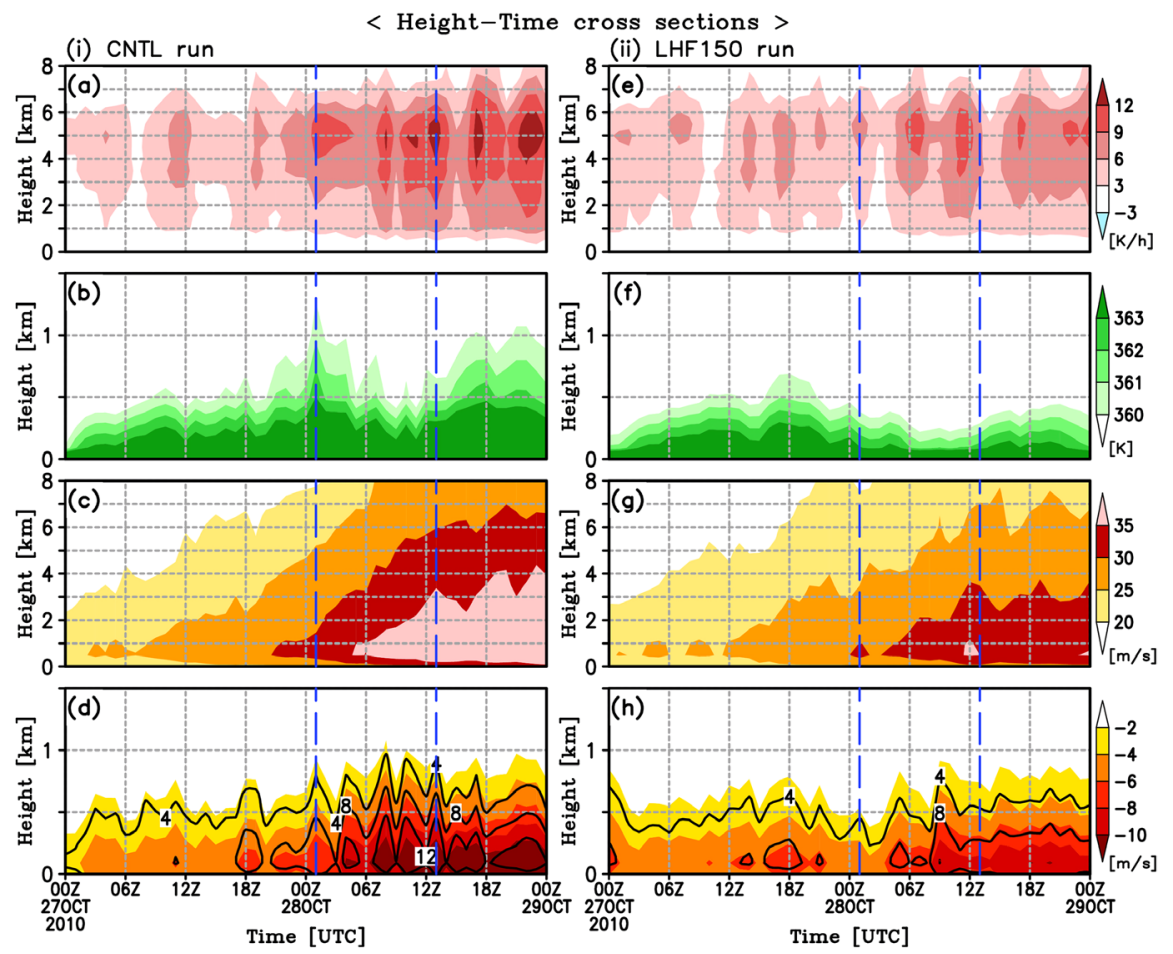

Fig. 5. Height-time cross sections of (a) latent heating rate (shading), (b) PBL- $\theta_{e}$ (shading), (c) tangential wind speed (shading), and (d) PBL inflow (shading) and radial AAM advection (contours; $4 \times 10^{5} \mathrm{~m}^{2} \mathrm{~s}^{-1} \mathrm{~h}^{-1}$ intervals) averaged within the TC inner core region in the CNTL run. Blue dashed lines denote 6 hours before and after the time of the maximum deepening rate. (e, f, g, and h) Same as in Figs. 5a, 5b, 5c, and 5d, but for the LHF150 run.

the LHF increase over the Kuroshio decelerated TC development in the LHF150 run. F2020 claimed that the PBL- $\theta_{e}$ decrease in the inner core could be attributable to the weakening of moisture transport from the Kuroshio. Thus, we focus specifically on the difference in the moisture transport from the Kuroshio toward the TC between the CNTL and LHF150 runs. Figure 6 shows the horizontal maps of vapor flux around the Kuroshio for the CNTL and LHF 150 runs and its difference between the two runs. The vapor flux was integrated vertically from the surface to a height of $1 \mathrm{~km}$. At 0100 and 1300 UTC, a remarkable moisture flux zone in excess of $300 \mathrm{~kg} \mathrm{~m}^{-1} \mathrm{~s}^{-1}$ stretched along the Kuroshio in the CNTL run (Figs. 6a and 6d). Interestingly, the southwestward vapor flux toward the TC markedly weakened in the LHF150 run (Figs. 6b and 6e). The difference in the southwestward flux over the Kuroshio between the two runs became apparent with time (Figs. 6c and 6f).

From the above results, another important question arises, as to why the moisture influx toward the TC was attenuated in spite of the LHF increase over the Kuroshio in the LHF150 run. In Fig. 6, we can find the enhancement of a cyclonic circulation of vapor flux over the eastern part of the Kuroshio (region A) in the LHF150 run. We expect that the moisture import toward the TC might be interrupted by the cyclonic circulation over the Kuroshio. Figure 7 a shows the differences in sea level pressure (SLP) and surface wind vectors between the CNTL and LHF150 runs at 1300 UTC on 28 October. A dipole anomaly of SLP around $130^{\circ} \mathrm{E}$ reflected a slightly eastward shift of the TC track in the LHF150 run. On the other hand, a distinctive negative SLP anomaly in excess of $6 \mathrm{hPa}$ was located over the region A. Precipitable water around the low pressure area was larger by $12 \mathrm{~mm}$ in the LHF 150 run than in the CNTL run (Fig. 7b), indicating that the surface low seen in the LHF150 run was accompanied by large amounts of vapor evaporated from the Kuroshio. To clarify a key factor for the reinforcement of the surface low, we examine the time series of the precipitable water, LH, and SLP averaged over the oceanic area within the region A. On 27 and 28 October, the region A was in a very moist condition in the LHF150 run (Fig. 7c). The wet environment contributed to stronger LH after approximately
0600 UTC on 27 October (Fig. 7d). We see that, in response to the LH enhancement, the SLP over the region A decreased; that is, a surface low developed. The intensified surface low can further accumulate the vapor evaporated from the Kuroshio, resulting in interrupting the moisture import from the Kuroshio toward the TC.

Another remarkable change between the two runs can be seen in the surface wind vectors over the southwestern part of the Kuroshio (region B). In the LHF150 run, northeastward anomalies of vapor flux and surface winds occurred along the Kuroshio concurrent with the intensified surface low (Figs. 6f and 7a). The surface winds and vapor flux averaged over the oceanic area within the region B became weak after approximately 1200 UTC on 27 October as compared with the CNTL run (Figs. 7e and 7f), leading to the suppression of the moisture influx toward the TC. The attenuated moisture import into the TC resulted in a decrease relative to the CNTL run in the PBL- $\theta_{e}$ within the TC inner core starting from approximately 1800 UTC on 27 October, as already indicated in Fig. 5f.

These features suggest that the attenuated moisture import caused the PBL- $\theta_{e}$ decrease within the inner core in the LHF150 run. Therefore, a series of this study's results was consistent with the conclusion of F2020 that the PBL- $\theta_{e}$ decrease in the TC inner core in association with the weakened moisture import played a vital role in suppressing TC intensification, although the reason for the change in the moisture import was different between the two studies.

\section{Summary}

We investigated the remote impacts of surface LHF increases over the Kuroshio on the development of Typhoon Chaba in 2010, which was the same TC analyzed in F2020. This study conducted two numerical simulations by using the $0.04^{\circ}$-resolution CReSS model; a control run with a real SST distribution (CNTL run) and a sensitivity experiment (LHF150 run) with an increased LHF over the Kuroshio larger than in the CNTL run by approximately 


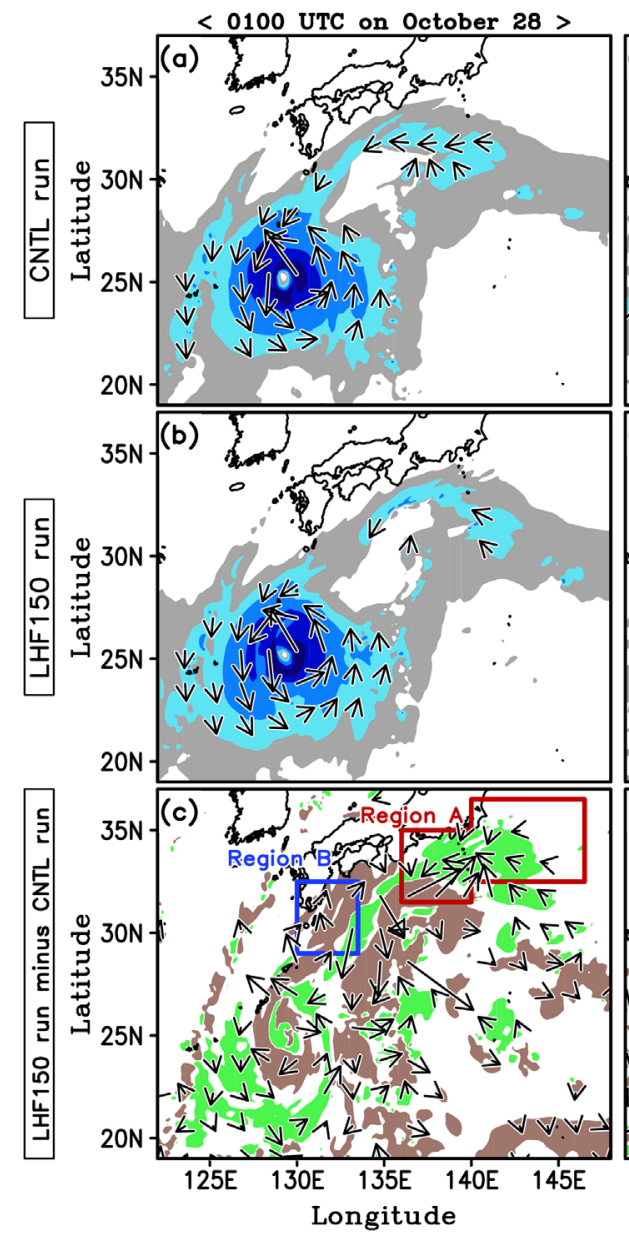

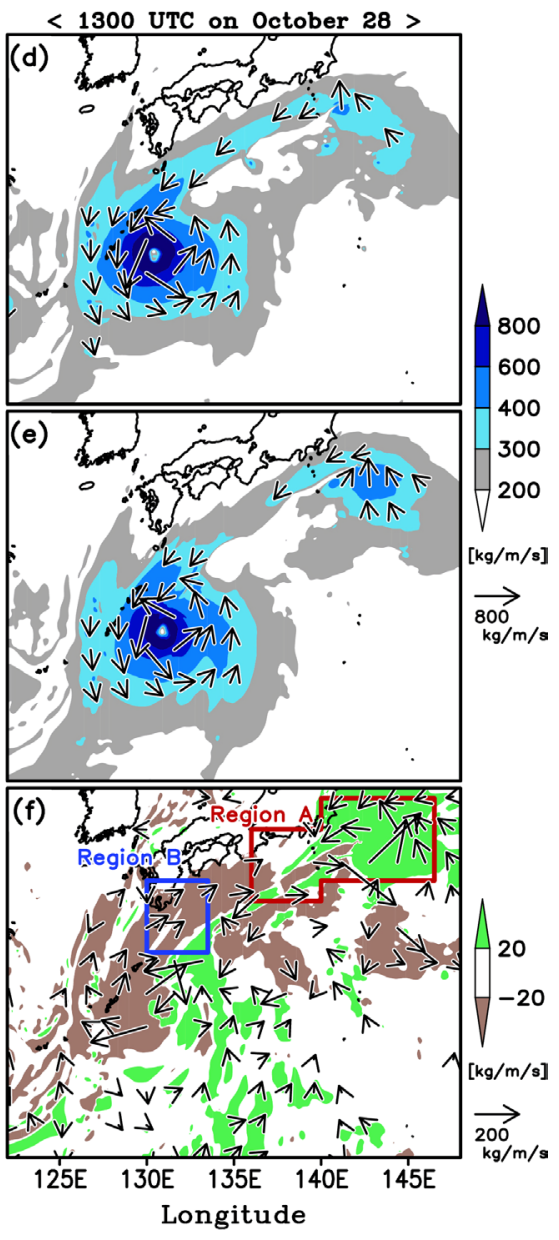

Fig. 6. (a and d) Horizontal maps of moisture flux (vectors) and its magnitude (shading) at 0100 UTC and 1300 UTC on 28 October 2010, for the CNTL run. The moisture flux is integrated from the surface to a height of $1 \mathrm{~km}$. Flux of less than $300 \mathrm{~kg} \mathrm{~m}^{-1} \mathrm{~s}^{-1}$ is not drawn. The reference arrow is $800 \mathrm{~kg} \mathrm{~m}^{-1} \mathrm{~s}^{-1}$. (b and e) Same as in Figs. 6a and $6 \mathrm{~d}$, but for the LHF150 run. (c and $\mathrm{f}$ ) The difference in moisture flux between the CNTL and the LHF150 runs (the latter minus the former). Flux anomaly of less than $20 \mathrm{~kg} \mathrm{~m}^{-1} \mathrm{~s}^{-1}$ is not drawn. The reference arrow is $200 \mathrm{~kg} \mathrm{~m}^{-1} \mathrm{~s}^{-1}$.

$<1300$ UTC on October $28>$

(a) Surface winds \& SLP

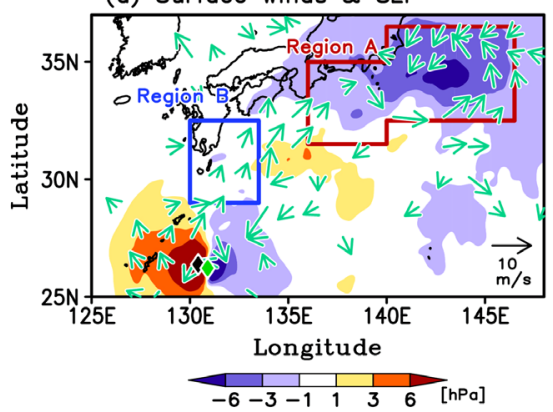

(c) Precipitable water $[\mathrm{mm}]$

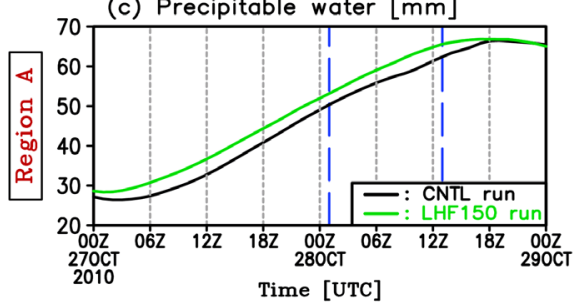

(e) Surface wind speed $[\mathrm{m} / \mathrm{s}]$

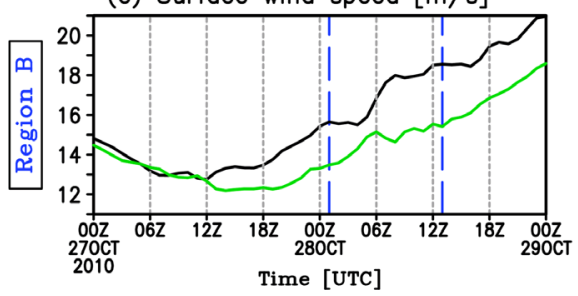

(b) Precipitable water \& SLP

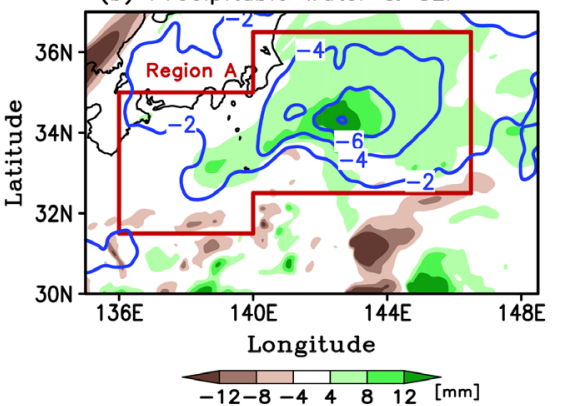

(d) $\mathrm{LH}\left[\times 10^{3} \mathrm{~W} / \mathrm{m}^{2}\right]$ \& SLP $[\mathrm{hPa}]$

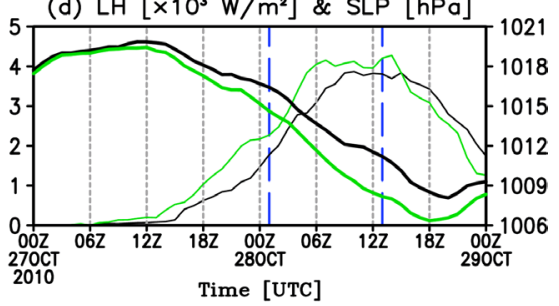

(f) Vapor flux $[\mathrm{kg} / \mathrm{m} / \mathrm{s}]$

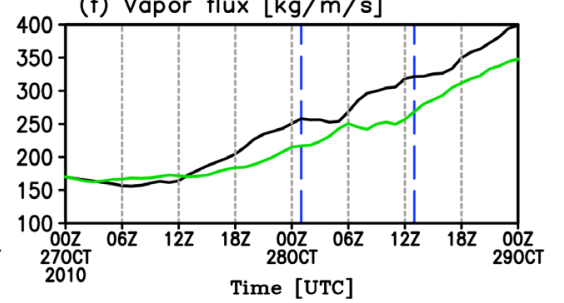

Fig. 7. (a) Differences in SLP (shading) and surface winds (vectors) between the CNTL and the LHF150 runs (the latter minus the former) at 1300 UTC on 28 October. The reference vector is $10 \mathrm{~m} \mathrm{~s}^{-1}$. Black and green diamonds denote the TC locations in the CNTL and the LHF150 runs, respectively. (b) Differences in precipitable water (shading) and SLP (contours; $2 \mathrm{hPa}$ intervals) between the CNTL and the LHF150 runs (the latter minus the former) at 1300 UTC on 28 October. (c) Time evolution of precipitable water over the region A for the CNTL (black line) and LHF150 (green line) runs. Blue dashed lines denote 6 hours before and after the time of the maximum deepening rate. (d) Time evolution of vertical integrated LH (thin lines) and SLP (thick lines) over the region $\mathrm{A}$. (e) Time evolution of surface wind speed over the region B for the CNTL (black line) and LHF150 (green line) runs. (f) Same as in Fig. $7 \mathrm{e}$, but for vapor flux. 
$50 \%$. In the LHF150 run, TC intensification was suppressed as compared with the CNTL run. Comparisons of the thermodynamic features of the TC between the two runs suggested that the decrease in the PBL- $\theta_{e}$ around the eyewall led to the weakening of eyewall LH and associated TC secondary circulation. The dynamic features in the LHF150 run showed smaller super-gradient winds than in the CNTL run. This is consistent with the reduction in the inward AAM advection within the PBL, relevant to a weak tendency of the PBL inflow. We also found that differences in the thermodynamic and dynamic features of the TC between the CNTL and LHF150 runs were triggered by the decrease in the moisture import from the Kuroshio. The increased LHF over the Kuroshio facilitated the genesis and development of a surface low through LH owing to vapor condensation. Subsequently, the developed low further accumulated the Kuroshio's vapor, and weakened the low-level northeasterly winds, resulting in interrupting moisture transport toward the TC. The suppression of the moisture import into the TC led to a decrease in the PBL- $\theta_{e}$ within the inner core. These results were consistent with the results of F2020, hence, supporting the conclusion that the import of moisture from the Kuroshio can remotely influence TC development over the western North Pacific.

This study has also presented that local disturbances over the Kuroshio may alter large-scale moisture flows in that vicinity, remotely affecting TCs approaching Japan. Although the LHF changes over the Kuroshio influence the genesis and activity of such disturbances, their relationships are very complicated because local condensation over the ocean depends strongly on thermodynamic atmospheric conditions. For instance, Makarieva et al. (2013) discussed that the alternating condensation intensity over the ocean and over large forest basins leads to alternating patterns of water vapor transport. Their discussion might be able to apply to the issue of how TCs compete for moisture flow with local disturbances over the Kuroshio. In any case, monitoring and predicting the local disturbances will provide useful information about the improvement of TC forecasting based on the accurate estimation of moisture influx toward the TC. This issue will be investigated in future work.

\section{Acknowledgments}

The authors thank Editor Masami Nonaka and two anonymous reviewers for their useful comments and suggestions. This research was supported by JSPS KAKENHI Grant Numbers JP19H05696 and JP20H00289.

Edited by: M. Nonaka

\section{References}

Braun, S. A., 2006: High-resolution simulation of Hurricane Bonnie (1998). Part II: Water budget. J. Atmos. Sci., 63, 4364.

Fujiwara, K., R. Kawamura, H. Hirata, T. Kawano, M. Kato, and T. Shinoda, 2017: A positive feedback process between tropical cyclone intensity and the moisture conveyor belt assessed with Lagrangian diagnostics. J. Geophys. Res. Atmos., 122, 12502-12521.

Fujiwara, K., R. Kawamura, and T. Kawano, 2020: Remote thermodynamic impact of the Kuroshio Current on a developing tropical cyclone over the western North Pacific in boreal fall. J. Geophys. Res. Atmos., 125, e2019JD031356.

Gentry, M. S., and G. M. Lackmann, 2010: Sensitivity of simulated tropical cyclone structure and intensity to horizontal resolution. Mon. Wea. Rev., 138, 688-704.

Hegde, A. K., R. Kawamura, and T. Kawano, 2016: Evidence for the significant role of sea surface temperature distributions over remote tropical oceans in tropical cyclone intensity. Climate Dyn., 47, 623-635.

Japan Meteorological Agency, 2013: Outline of the operational numerical weather prediction at the Japan Meteorological Agency. (Available online at http://www.jma.go.jp/jma/jmaeng/jma-center/nwp/outline2013-nwp/index.htm, accessed 27 April 2020).

Kepert, J., 2001: The dynamics of boundary layer jets within the tropical cyclone core. Part I: Linear theory. J. Atmos. Sci., 58, 2469-2484.

Krishnamurti, T. N., S. Pattnaik, L. Stefanova, T. S. V. Vijaya Kumar, B. P. Mackey, and A. J. O'Shay, 2005: The hurricane intensity issue. Mon. Wea. Rev., 133, 1886-1912.

Kudo, T., R. Kawamura, H. Hirata, K. Ichiyanagi, M. Tanoue, and K. Yoshimura, 2014: Large-scale vapor transport of remotely evaporated seawater by a Rossby wave response to typhoon forcing during the Baiu/Meiyu season as revealed by the JRA-55 reanalysis. J. Geophys. Res. Atmos., 119, 8825-8838.

Makarieva, A. M., V. G. Gorshkov, and B.-L. Li., 2013: Revisiting forest impact on atmospheric water vapor transport and precipitation. Theor. Appl. Climatol., 111, 79-96.

Makarieva, A. M., V. G. Gorshkov, A. V. Nefiodov, A. V. Chikunov, D. Sheil, A. D. Nobre, and B. L. Li, 2017: Fuel for cyclones: The water vapor budget of a hurricane as dependent on its movement. Atmos. Res., 193, 216-230.

Qin, N., D.-L. Zhang, W. Miller, and C. Q. Kieu, 2018: On the rapid intensification of Hurricane Wilma (2005). Part IV: Inner-core dynamics during the steady radius of maximum wind stage. Quart. J. Roy. Meteor. Soc., 144, 2508-2523.

Reynolds, R. W., T. M. Smith, C. Liu, D. B. Chelton, K. S. Casey, and M. G. Schlax, 2007: Daily high-resolution-blended analyses for sea surface temperature. J. Climate, 20, 54735496.

Riemer, M., M. T. Montgomery, and M. E. Nicholls, 2010: A new paradigm for intensity modification of tropical cyclones: Thermodynamic impact of vertical wind shear on the inflow layer. Atmos. Chem. Phys., 10, 3163-3188.

Smith, R. K., and M. T. Montgomery, 2015: Toward clarity on understanding tropical cyclone intensification. J. Atmos. Sci., 72, 3020-3031.

Smith, R. K., M. T. Montgomery, and J. Persing, 2014: On steadystate tropical cyclones. Quart. J. Roy. Meteor. Soc., 140, 2638-2649.

Smith, R. K., M. T. Montgomery, and S. V. Nguyen, 2009: Tropical cyclone spin-up revisited. Quart. J. Roy. Meteor. Soc., 135, 1321-1335.

Takakura, T., R. Kawamura, T. Kawano, K. Ichiyanagi, M. Tanoue, and K. Yoshimura, 2018: An estimation of water origins in the vicinity of a tropical cyclone's center and associated dynamic processes. Climate Dyn., 50, 555-569.

Tomita, H., T. Hihara, S. Kako, M. Kubota, and K. Kutsuwada, 2019: An introduction to J-OFURO3, a third-generation Japanese ocean flux data set using remote-sensing observations. J. Oceanogr., 75, 171-194.

Tsuboki, K., and A. Sakakibara, 2002: Large-scale parallel computing of cloud resolving storm simulator. High Performance Computing, H. P. Zima et al., Eds., Springer, New York, 243-259.

Yang, M. J., S. A. Braun, and D. S. Chen, 2011: Water budget of Typhoon Nari (2001). Mon. Wea. Rev., 139, 3809-3828.

Zhang, D.-L., Y. Liu, and M. K. Yau, 2001: A multiscale numerical study of Hurricane Andrew (1992). Part IV: Unbalanced flows. Mon. Wea. Rev., 129, 92-107.

Manuscript received 27 April 2020, accepted 22 June 2020

SOLA: https://www.jstage.jst.go.jp/browse/solal 